Síntese das reflexões da reunião sobre ética em pesquisa qualitativa em Saúde, Guarujá, SP

Synthesis of the reflections of the meeting on ethics in qualitative health research, Guarujá, São Paulo State

Abstract This article presents a synthesis of the report collectively elaborated in the meeting on Ethics in Q ualitative H ealth Research, which took place in Guarujá, São Paulo State, from August 28 to 30 , in 2006. The meeting was organized by the Ethical Committee of the M unicipal H ealth Office of São Paulo, supported by the Special Programme for Research and Training in Tropical Diseases (TDR), sponsored by UNICEF/U NDP/World Bank/WHO and stressed the need to review the Brazilian guidelines for the analysis of the ethical aspects of qualitative health research.

Key words Ethics, Qualitative research, Ethics committee
Resumo Este artigo apresenta uma síntese do relatório elaborado col etivamente na reunião sobre Ética em Pesquisa Qualitativa em Saúde, realizada no Guarujá, de 28 a 30 de agosto de 2006. Organizada pelo Comitê de Ética em Pesquisa da Secretaria M unicipal de Saúde de São Paulo- CEP/SM S, com apoio do Special Programme for Research and Training in Tropical Diseases(TDR), sponsored by U NICEF/U NDP/ World Bank/WHO, a reunião apontou a necessidade de revisar as diretrizes brasileiras para análise dos aspectos éticos das pesquisas qualitativas em saúde.

Palavras-chave Ética, Pesquisa Qualitativa, Comitê de ética 
Considerações preliminares sobrepesquisa qualitativa

A metodologia qualitativa vem sendo cada vez maisutilizada evalorizada nas pesquisas em Saú$\mathrm{de}^{1,2,3,4}$ no país e internacionalmente ${ }^{5}, 0$ que torna ainda mais premente a necessidade de levar sua especificidade em consideração, inclusive no momento da revisão de seus aspectos éticos.

A pesquisa qualitativa éum campo de estudo em $\mathrm{si}^{1,6}$. A pesquisa qualitativa pode ser considerada como um conjunto de atividades interpretativas, que não privilegia uma técnica sobre a outra, podendo mesmo adotar técnicas diferentes em um mesmo estudo. N ão possui um paradigma que lhe seja específico e muitas disciplinas e teorias vêm adotando abordagens qualitativas $^{7,3,6,8}$. Os usos e significados múltiplos dos métodos de pesquisa qualitativa também tornam difícil aos pesquisadores que concordem com uma única definição do campo, visto queelenunca éúnico ${ }^{6}$.

Já na terminologia para designá-la encontrase diversidade. Autores de língua inglesa $a^{6,9,10,11}$ usualmente se referem a "qualitative research", ou no nosso caso específico "qualitative health research"12. Nos textos em português, tenho observado termos como: "metodologias de pesquisa qualitativa" ${ }^{3}$, "abordagens qualitativas" ${ }^{1}$, "investigações qualitativas" ${ }^{2}$. Isso aponta que a diversidade não é só na maneira de denominála, mas também de concebêla.

M inayo ${ }^{3}$ considera que [...] as metodologias de pesquisa qualitativa não constituem em si ideologia ou uma corrente de pensamento. Pelo contrário, descrevo-as como componentes das principais linhas teóricas das Ciências Sociaise, em cada uma delas, submetidas a uma organização e pressupostos peculiares.

Também há diversidade de técnicas de coleta de dados, incluindo-se entre as mais adotadas a entrevista, a observação participante, o grupo focal, a historia de vida ${ }^{4,13}$. Além disso, a maneira como cada uma é adotada também pode variar. Para exemplificar, podemos tomar a entrevista. 0 pesquisador pode conduzi-la de maneira a seguir livremente a fala do pesquisado (entrevistas abertas), até valer-se de questionários estruturados (sondagem de opinião). Várias nuanças entre a entrevista aberta e a estruturada são possíveis. $M$ inayo ${ }^{13}$ propõe, além destas citadas, a se guinte classificação: entrevista semi-estruturada (combina perguntas abertas e fechadas), entrevista focalizada (foca uma questão específica) e entrevista projetiva (utilização de um dispositivo visual como foto, filme, etc. e convida-se o pesquisado a falar sobre o quevê). A escolha sobre a técnica a ser utilizada, de que maneira será realizada e como o material será analisado está relacionada ao referencial teórico adotado eaos objetivos da pesquisa. I dentificar os referenciais teóricos que subsidiam as pesquisas qualitativas éfundamental para se entender a pesquisa qualitativa como campo ${ }^{1}$. É importante recuperar estas idéias neste texto, pois não é possível conduzir uma pesquisa qualitativa com qualidade se esta não estiver firmemente calcada em pressupostos teóricos, usualmente explicitados pelo pesquisador tanto no projeto quanto na apresentação dos resultados. É uma obrigação ética do pesquisador, em especial quando seus objetos de estudo não se encaixam nos moldes cartesianos, mostrar como pensou. Trata-se de elucidar, "pensar o que fazem e saber 0 que pensam ${ }^{14}$. Este ponto não será desenvolvido neste texto, pois foge muito de seu propósito, mas éimportante colocar a preocupação e talvez mesmo a suposição de que problemas éticos observados na pesquisa qualitativa sejam relacionados ao fato de que suas técnicas sejam utilizadas sem estarem acompanhadas de uma profunda reflexão teórica. M ais ou menos como cortar uma árvore e transplantá-la, sem levar junto suas raízes. N estecaso, a possibilidade da árvore cair e causar danos às pessoas é muito grande; diferenteda árvore quetem raízes sólidas e pode proporcionar sombra, flores, frutos. Isso fica como um pano de fundo para a discussão sobre se a ética éintrínseca às pesquisas qual itativas $^{5,15,7,6}$ pois, ainda que caiba discussão sobre esta afirmação, para iniciá-la é necessário complementar esta frase: a ética éintrínseca à pesquisa qualitativa consistente e bem conduzida.

A intenção desta brevereflexão sobrea diversidade presente no campo da pesquisa qualitativa é afirmar que deste 0 início da organização desta reunião, havia clareza que entre seus participantes não haveria consenso sobre este campo.

0 desafio era discutir ética nas pesquisas qualitativas em saúde, considerando esta diversidade. De saída, observamos que a falta de consenso sobre uma definição única do que seja "pesquisa qualitativa" coloca ao grupo um primeiro desafio, que é o de construir coletivamente minimamente quais seriam as características das pesquisas qualitativas, para que pudéssemos discutir os aspectos éticos das mesmas.

Por outro lado, esta discussão dialogou com as resoluções do Conselho $\mathrm{N}$ acional de Saúde sobre ética em pesquisa com seres humanos, a saber, a Resolução 196/96 e suas complementa- 
res. Era consensual, entre os participantes que conduzem pesquisas qualitativas, certo desconforto frenteàs diretrizes brasileiras, quenão contemplam as especificidades destas pesquisas. I sso porque, embora não haja consenso sobre a pesquisa qualitativa, havia clareza quea definição de pesquisa presente na Resolução 196/96 não contemplava esta diversidade. Inclui-se ainda que a concepção deindivíduo presentenesta resolução possibilita uma compreensão muito singular do que seja autonomia.

\section{A reunião}

A reunião do Guarujá teve por objetivo discutir os aspectos éticos da pesquisa qual itativa em saúde, considerando suas especificidades. Os participantes foram indicados por instituições deporte nacional, tais como: M inistério da Saúde, Associação Brasileira de Pós-Graduação em Saúde Coletiva (ABRASCO), Associação Brasileira de Antropologia (ABA), Associação Nacional de Pesquisa ePós-graduação em Psicologia (AN PE$P P)$, Sociedade Brasileira de Bioética (SBB), entre outras que estão citadas ao final do relatório. Integrantes do M inistério Público Federal também acompanharam os trabalhos. H ouve a participação de editores de revistas importantes no campo da Saúde Col etiva ede pesquisadores franceses e canadense; o presidente da Associação Americana de Psicologia também compareceu. Os participantes tinham em comum sua vasta experiência na área. Entretanto, tinham formações básicas diferentes: sociólogos, antropólogos, psicólogos, médicos, enfermeiros, biólogos, entre outros, e adotavam referenciais teóricos diversos. Havia, portanto, uma rica diversidade, que aprimorava os debates.

A reunião foi organizada em cinco períodos quese iniciavam com a exposição sobre um tema, já desenvolvido em um texto que havia sido previamente encomendado e distribuído aos participantes; em seguida, abria-se para o debate. Havia um relator designado para tomar notas de cada um dos cinco debates que se processaram. A reunião foi gravada na íntegra e depois transcrita. 0 sexto e último período da reunião foi utilizado para apresentação das notas dos debatedores e discussão das sugestões que poderiam ser enviadas ao Conselho Nacional de Saúde.

Após a reunião, com bases nos textos dos relatores e na transcrição dos debates, foi elaborada uma primeira versão do relatório, que foi discutida junto aos cinco relatores; o texto que resultou deste trabal ho foi enviado aos trinta participantes da reunião do Guarujá. M esmo entre estes que estiveram presente na reunião, não houve consenso, e quando este não foi alcançado, mantivemos no relatório a opinião da maioria. A pós análise esíntese das contribuições destes participantes, esta nova versão foi enviada a todos os Comitês de Ética do país, localizados a partir do site da Comissão Nacional de Ética em Pesquisa (CONEP). Novamente as sugestões recebidas foram analisadas e incorporadas, na medida em que não mudassem o conteúdo acordado na reunião realizada.

A versão final deste relatório foi enviada em 31 de outubro de 2007 para o Consel ho Nacional de Saúde (CNS) solicitando apreciação. A proposta do relatório indica a necessidade de diretrizes específicas para estas pesquisas. Este relatório pode ser acessado pelo site: http://portal. prefeitura.sp.gov.br/secretarias/saude/cepsms ou solicitado pelo e-mail iarag@uol.com.br.

\section{O relatório}

O relatório do Guarujá16 não está estruturado de acordo com um referencial teórico específico, uma vez que este foi uma construção coletiva. Possivel mente cada um dos autores que colaboraram na elaboração do mesmo, se fosse escrever individualmente, desenvolveria uma discussão baseada no seu referencial teórico ediscutiria a partir de sua prática ao conduzir pesquisa qualitativa. Assim, o relatório adota como interlocutor privilegiado aqueles que não estão familiarizados com a pesquisa qualitativa, apontando um conjunto de características que lhe são próprias e explicitando sua diferença em relação à concepção de pesquisa presente na Resolução 196/96 e suas complementares.

A seguir, alguns trechos do relatório:

1. Ao analisar se o princípio de autonomia foi ou não respeitado, é fundamental considerar quea concepção de sujeito é intrínseca à sua pertinência a um dado grupo social e não pode ser desvinculada deste. 0 indivíduo é sempre em contexto. Portanto, o pesquisador tem a responsabilidade de pactuar as questões éticas de seu estudo também junto à comunidade estudada e nem sempre será pertinente a assinatura de um termo de consentimento individual por escrito.

2. A pesquisa qualitativa busca abordar eanalisar como os seus participantes compreendem e agem no mundo, o quenão implica a formulação de afirmações a priori; ao contrário, o pesquisa- 
dor deve se engajar, tomar decisões sobre 0 andamento do estudo e tirar suas conclusões tendo como referência o processo de coleta de dados, quefoi discutido com seus interlocutores - participantes das pesquisas. Isso significa dizer que 0 problema, ou os problemas da pesquisa, bem como a estratégia para obter esses dados podem ir se modificando de acordo com a perspectiva dos participantes e 0 andamento da mesma. Portanto, cabe destacar dois aspectos: a) as pesquisas qualitativas têm um caráter emergente, pois se trata de uma construção conjunta entre o pesquisador e o pesquisado, sendo que as decisões são negociadas, freqüentemente, entre ambos; b) estetipo de pesquisa não implica necessariamente em proposição e teste de hipóteses.

3. A pesquisa qualitativa só tem mérito científico se o outro for ouvido, situado e compreendido em seu contexto cotidiano - ou seja, não é possível fazer um experimento, isolando fatosespecíficos, ou retirar o pesquisado do seu contexto, ou ainda distinguir fato e valor, buscando causalidades lineares. M esmo a pessoa do pesquisador, com suas crenças e val ores, não pode ser excluída de sua relação com o pesquisado. Sendo assim, as informações geradas na pesquisa estão indissociavelmenteligadas à relação constituída entrepesquisador e pesquisado e sua comunidade.

4. A pesquisa qualitativa não visa generalizações nos mesmos termos que aquela que envolve cálculo amostral. Por isso, um dos critérios usualmenteadotado éo da saturação teórica, ou seja, quando o conteúdo expresso pelos pesquisados começa a se repetir, o pesquisador pára de coletar dados. Desta maneira, freqüentemente, éimpossível prever, no momento de elaboração do projeto, o número de pesquisados a serem incluídos no estudo.

5. 0 consentimento livreeinformado do participante da pesquisa é fundamental, mas é importante que respeite o padrão cultural dos pesquisados e seja obtido nos moldes negociados entre pesquisador e pesquisado(s), sem que seja necessariamente por escrito.

6. A privacidadeéum conceito inexistenteem muitas culturas, como entrealgumas etnias indígenas. Determinados grupos sociais ou comunidades vivem muito mais num contexto (setting) coletivo do que dual. Assim, não só não haveria problema em fazer uma entrevista ou colher um depoimento na presença de outros, como esta presença seria um apoio importante para o entrevistado no seu ato de narrar.

7. Os resultados devem ser apresentados pelo pesquisador para os pesquisados, de maneira compreensível. 0 pesquisador pode identificar junto à comunidade pesquisada "produtos" de interesse desta, como a elaboração de uma publicação em linguagem acessível eabordando temas de interesse para os pesquisados, a ser distribuída na comunidade.

$\mathrm{N}$ a publicação dos resultados, é usual que pesquisadores citem trechos dos relatos de seus pesquisados. É ética emetodologicamenteessencial que o pesquisador tenha cuidado para não distorcer as afirmações dos pesquisados.

Os pesquisadores freqüentemente enviam a análise que fizeram para que os pesquisados verifiquem se foram adequadamente representados.

$\mathrm{N}$ a publicação dos resultados, é possível que o pesquisador negocie com pesquisados a pertinência de co-autoria.

Há estudos em que o retorno dos resultados é parte do próprio processo da pesquisa, como na pesquisa-ação.

Por outro lado, éinegável que al gumas análises de caráter mais teórico e acadêmico podem prescindir do retorno, até por desinteresse dos indivíduos ou do grupo.

\section{Considerações finais}

H oje, após a reunião e estelongo período de elaboração deste relatório, observo que a pesquisa qualitativa, ao ser adotada por profissionais com diferentes formações e que adotam diferentes referenciais teóricos, podesemodificar eassumir diferentes características. Isso acontece em especial no campo da Saúde Coletiva, que tem um enfoque transdisciplinar. Creio que esta diversidademereceestudo em si, em especial sobrequais abordagens qualitativas, bem como seu referencial teórico, vem sendo incorporadas pelos pesquisadores que atuam na área de saúde coletiva. E quais são as implicações éticas destas modificações? Assim, concluo este texto ressaltando a importância de manter este debate em pauta e apontando a necessidade de revisão das diretrizes sobre ética em pesquisa, de maneira que estas considerem a especificidade da pesquisa qualitativa em saúde. 


\section{Referências}

1. Nunes ED. A metodologia qualitativa em saúde: dilemas e desafios. In: Barros NF, Cecatti JG, Turato ER. Pesquisa qualitativa em saúde. Campinas: UNICAM P; 2005. p. 15-24.

2. Turato ER. Conceitos de pesquisa qualitativa em saúde mental. In: Barros NF, Cecatti JG, Turato ER. Pesquisa qualitativa em saúde. Campinas: UNICAMP; 2005. p. 27-35.

3. M inayo M CS. 0 desafio do conhecimento científico pesquisa qualitativa em saúde. 3ạ ed. São Paulo: Hucitec; Rio de Janeiro: Abrasco; 1994.

4. Víctora CG, Knauth DR, Hassen MNA, Agra MN Pesquisa qualitativa em saúde. Porto Alegre: Tomo Editorial; 2000.

5. van den Hoonard W. Trends in Canadian Sociology Master's Theses in Relation to Research Ethics Review, 1995-2004. Journal of Empirical Research on Human Research Ethics 2006; 1(4):77-88.

6. Denzin N, Lincoln YS, editors. Handbook of Qualitative Research. $2^{\text {nd }}$ ed. Thousand Oaks: Sage; 2000.

7. Guerriero ICZ. Aspectos éticos das pesquisas qualitativas em saúde [tese]. São Paulo (SP): Faculdade de Saúde Pública/Universidade do Estado de São PauIo; 2006.

8. Canesqui AM. A pesquisa qualitativa antropológica na saúde coletiva. In: Barros NF, Cecatti JG, Turato ER. Pesquisa qualitativa em saúde. Campinas: UNICAMP; 2005.p. 247- 259.

9. Guba EG, Lincoln YS. Fourth generation evaluation. N ewbury Park: Sage; 1989.
10. Kvale S. Interviews. An introduction to qualitative research interviewing. Thousand Oaks: Sage; 1996.

11. Christians CG. Ethics and politics in qualitative research. In: Denzin NK, Lincoln YS, editors. $\mathrm{H}$ andbook of Qualitative Research. $2^{\text {nd }} \mathrm{ed}$. Thousand Oaks: Sage; 2000. p. 133-155.

12. M orse J. Reasons for rejection/reasons for acceptance. Qual Health Res [serial on the Internet] 2007 [cited 2007 Nov]. Available from: http://qhr.sagepub. $\mathrm{com} / \mathrm{cgi} /$ reprint/17/9/1163

13. M inayo M CS, Assis SG, Souza ER, organizadoras. Avaliação por triangulação de métodos: abordagem de programas sociais. Rio de Janeiro: FIOCRUZ; 2005.

14. Campos RO. Pesquisa qualitativa em políticas, planejamento e gestão em saúde coletiva. In: Barros NF, Cecatti JG, Turato ER. Pesquisa qualitativa em saúde. Campinas: UNICAM P; 2005. p. 261- 271.

15. Macedo RMS. Diretrizes éticas e pesquisas qualitativas em Saúde. Rev C S Col. No prelo 2007.

16. Secretaria Municipal de Saúde de São Paulo. Relatório da reunião sobre ética em pesquisa qualitativa em Saúde, realizada no Guarujá, de 28 a 30 de agosto de 2006 [acessado 2007 N ov 06]. Disponível em: http://portal.prefeitura.sp.gov.br/secretarias/ saude/cepsms/

Artigo apresentado em 08/11/2007 Aprovado em 12/12/2007 